\title{
- Geophysical evidence for crustal and mantle weak zones controlling intra-plate seismicity - the 2017 Botswana earthquake sequence
}

\author{
Max Moorkamp ${ }^{\mathrm{a}, \mathrm{b}}$, Stewart Fishwick ${ }^{\mathrm{a}}$, Richard J. Walker ${ }^{\mathrm{a}}$, \& Alan G. \\ Jones $^{\mathrm{c}}$ \\ ${ }^{a}$ School of Geography, Geology and the Environment, University of Leicester, University \\ Road, Leicester LE1 7RH, UK \\ ${ }^{b}$ now at: Ludwig-Maximilians-Universität, Department of of Earth and Environmental \\ Sciences, Theresienstrasse 41, 80333 Munich, Germany \\ ${ }^{c}$ Complete MT Solutions Inc., Ottawa Canada. Formerly Dublin Institute for Advanced \\ Studies, Dublin, Ireland
}

\section{Abstract}

Large earthquakes away from plate boundaries pose a significant threat to human lives and infrastructure, but such events typically occur on previously unknown faults. Most cases of intra-plate seismicity result from compression related to far-field plate boundary stresses. The April $2017 \mathrm{M}_{\mathrm{W}} 6.5$ earthquake in central Botswana, and subsequent events, occurred in a region with no previously known large earthquakes, occurred away from major present day tectonic activity, and accommodate extension rather than compression. Here, we present results from an integrated geophysical study that suggests the recent earthquakes may be a sign of future activity, controlled by the collocation of a weak upper mantle and weak crustal structure, between otherwise strong Precambrian blocks. Magnetotelluric data highlights Proterozoic continent accretion structure within the region, and shows that recent extension and seismicity occurred along ancient thrust faults within the crust. Our seismic velocity and resistivity models suggest a weak zone in the uppermost mantle, that does not persist to greater depths, and is therefore unlikely to represent mantle upwelling. The Botswana events may therefore be indicative of top-down extension as a response to large scale extensional forces.

Email address: Max.Moorkamp@lmu.de (Max Moorkamp )

Preprint submitted to Elsevier

October 26, 2018 


\section{Introduction}

The 3rd April 2017 Botswana earthquake (moment magnitude, $\mathrm{M}_{\mathrm{W}}$ 6.5) was the largest event on the African continent outside the East African Rift System (EARS) for over 80 years (cf [1]) (Figure 1). It was part of a sequence of 15 events with magnitudes up to $\mathrm{M}_{\mathrm{W}} 5$. That sequence lasted for 4 months following the main event, with the final event occurring $200 \mathrm{~km}$ away on 12 th August 2017. Intra-plate earthquakes require sufficient stress to build-up, with most events attributed to far-field effects of deformation at plate boundaries [2]. Given that stable continental lithosphere is rigid and strong, these stresses can be transferred over long distances [3]. Such a model of earthquake generation is compatible with thrusting or strike-slip mechanisms and general horizontal contraction, which is observed in most intra-plate events [4].

The Botswana event is different in this respect as its focal mechanism indicates normal faulting and extension. However, such a mechanism is consistent with stress and stress-gradient calculations for southern Africa $[5,6]$ which indicate large scale extension. Controls on the precise locations of intra-plate events remain debated. Tectonic controls, such as gradients in lithospheric thickness and the presence of weak zones may facilitate movement [7]. For example, earthquakes in the New Madrid Seismic Zone, USA, are thought to be associated with pre-existing faults and possibly a weak mantle below [8]. Recent work suggests that these large scale factors determine the style of faulting and the stress release, while transient events, possibly due to non-tectonic forces, are responsible for triggering the earthquake [9]. For the Botswana earthquake it has been hypothesized that fluid leaks from the upper mantle have triggered the event [10].

Although Botswana does not show any strong earthquakes in instrumented history, the clustering of small magnitude events in the Okavango delta in northern Botswana has led to speculation of an incipient rift [13] - the Okavango Rift Zone (ORZ) [14] - which may represent the southwestern continuation of the EARS [15]. Most of the current understanding of the deeper crustal and upper 


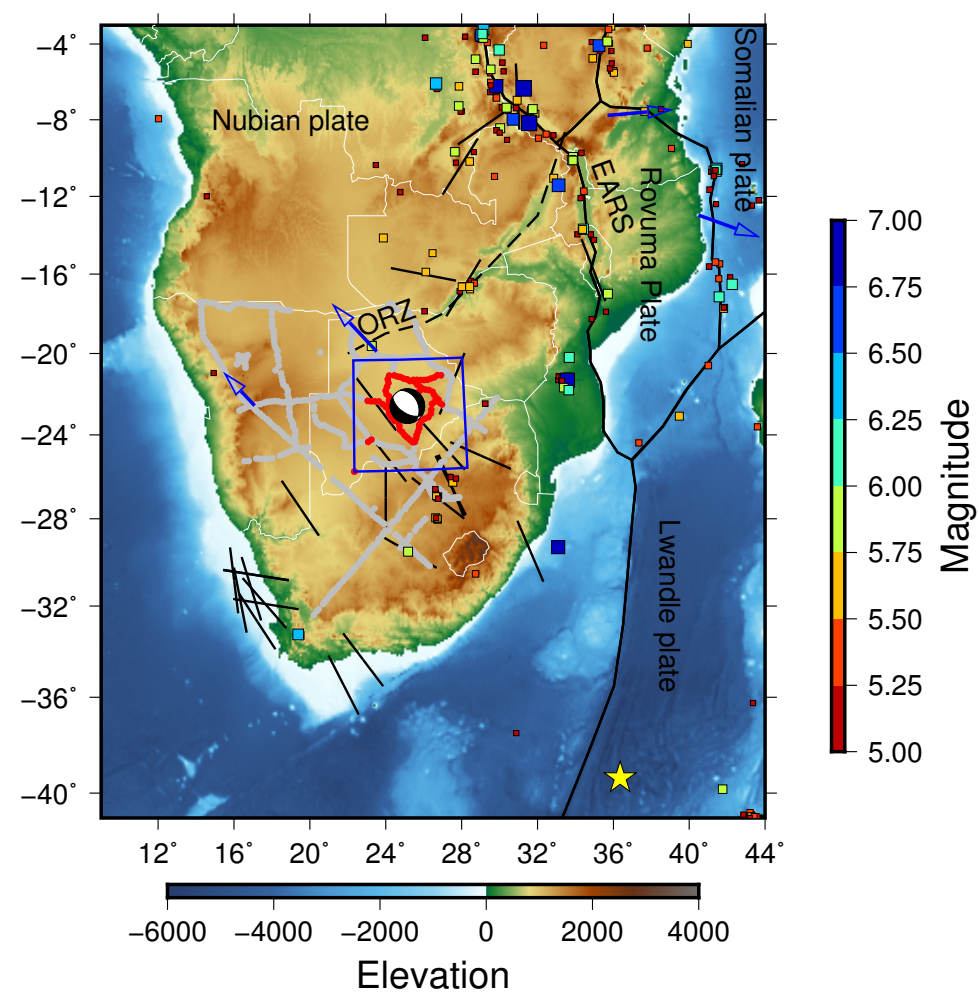

Figure 1: Map of southern and central Africa. The study area is shown with a blue rectangle and we show the location and focal mechanism of the 03/04/2017 earthquake. Black lines show plate boundaries whereas the dashed line indicates the proposed south-western continuation of the East African Rift System (EARS) to the Okavango Rift Zone (ORZ). Colored boxes show all seismic events in the USGS earthquake catalogue with moment magnitude $>5$, where color and size indicate magnitude. Black bars indicate maximum horizontal stress direction from the World Stress Map[11]. Blue arrows show inferred plate motion with respect to the Nubian plate[12] and the yellow star marks the Euler pole for the Somalia-Nubia plate motion. The locations of the SAMTEX MT sites are shown in grey and red circles, where the red ones are modelled in this paper. 
mantle structures in the region is based on a profile of magnetotelluric (MT) data to the east [16], and inversion of receiver functions [17], shear wave splitting analysis [18], and seismic tomography [15] along the profile of the SAFARI experiment. Potential field data have been used to identify the boundaries between different tectonic units $[14,19]$, but significant uncertainty remains as to the location and nature of those units (compare [14, 16, 18, 20, 21]).

\section{Inverting magnetotelluric and surface wave data}

Here we present 3D models of the lithosphere south of the ORZ and centered on the April 2017 event, based on MT measurements (e.g. [22]) and regional surface wave data. We use magnetotelluric transfer functions from 81 stations in the vicinity of the hypocentre (Figure 1) from the publicly available SAMTEX dataset[23], and invert them using the 3D inversion methodology described in [24] that includes correction for static distortion [25]. We select data at 24 periods between $1 \mathrm{~s}$ and $600 \mathrm{~s}$ corresponding to depths between $5 \mathrm{~km}$ and $80 \mathrm{~km}$ as confirmed by sensitivity tests (see supplementary material). We start the inversion with a high smoothing regularization term to recover the broad conductivity structure and successively lower the weight of the regularization until we achieve an adequate fit to the observed data. The final inversion model (Figures 2 and 3) explains the data to a RMS of 1.3 assuming an error floor of $2 \%$ of the Berdichevsky invariant of the impedances. This choice of error floor down-weights small diagonal elements in the inversion, but has the advantage of making the misfit rotationally invariant. Still we observe an excellent fit to all elements of the impedance tensor.

Figure 4 shows a representative selection of magnetotelluric data and the associated model fits. Stations 24 and 25 (top row in Figure 4) are located closest to the epicentre of the 3rd April event and show excellent fit for all components across the whole frequency range. Station 5 (bottom left in Figure 4) is located close to the 12th August event and shows a good fit for all components and frequencies. Station 79 (bottom right in Figure 4) is the site with highest 

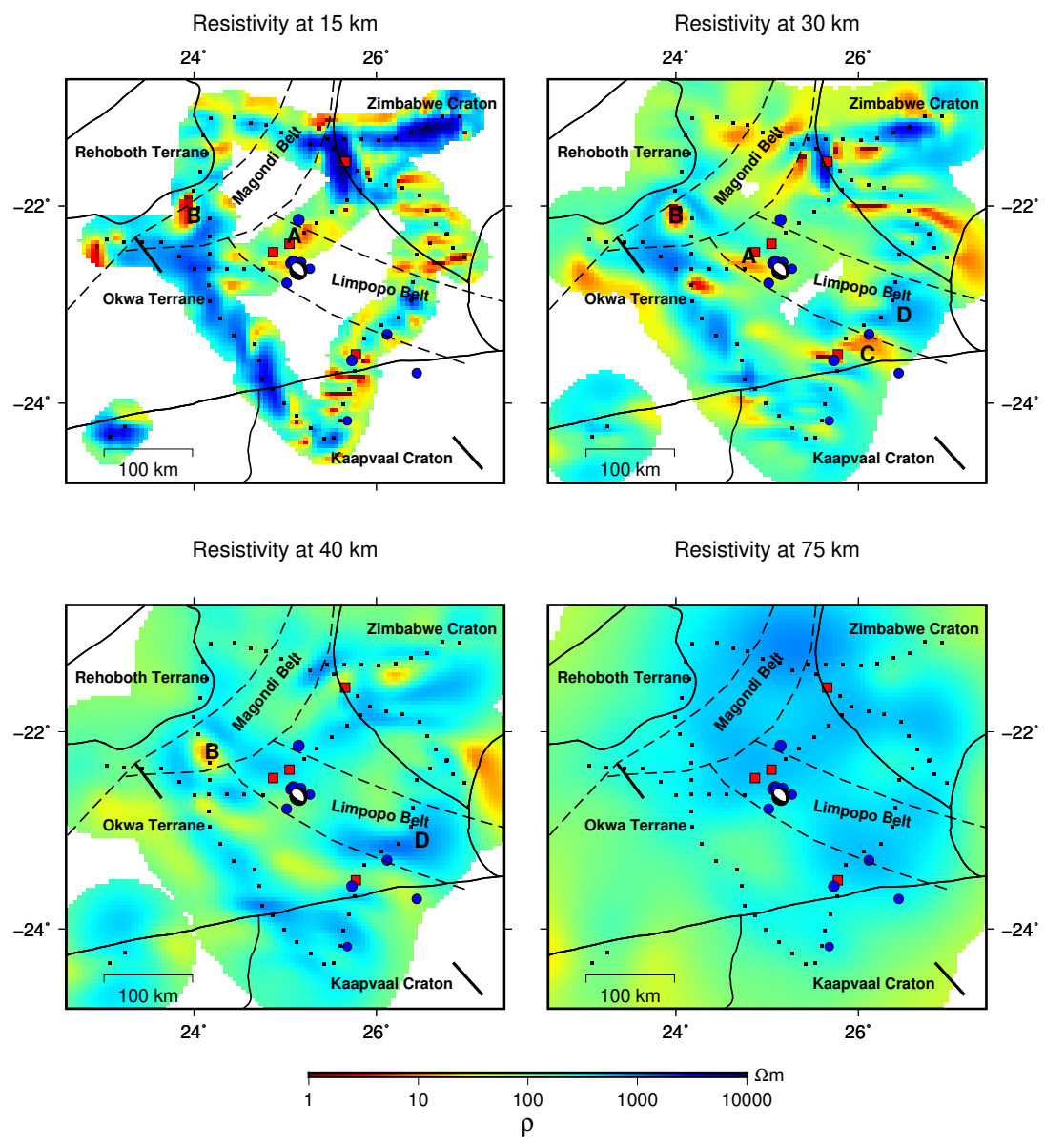

Figure 2: Horizontal slices through our preferred resistivity model. The magnetotelluric stations used in the inversion are marked as black squares. We show the location and focal mechanism of the April recent earthquake as well as the location of seismicity in the area (blue dots) and the August 2017 magnitude 5 event (red dot). Solid black lines show the boundaries of tectonic units with additional crustal units from [26] (dashed lines). Thick black bars show the direction of maximum horizontal stress from the world stress map[11]. 


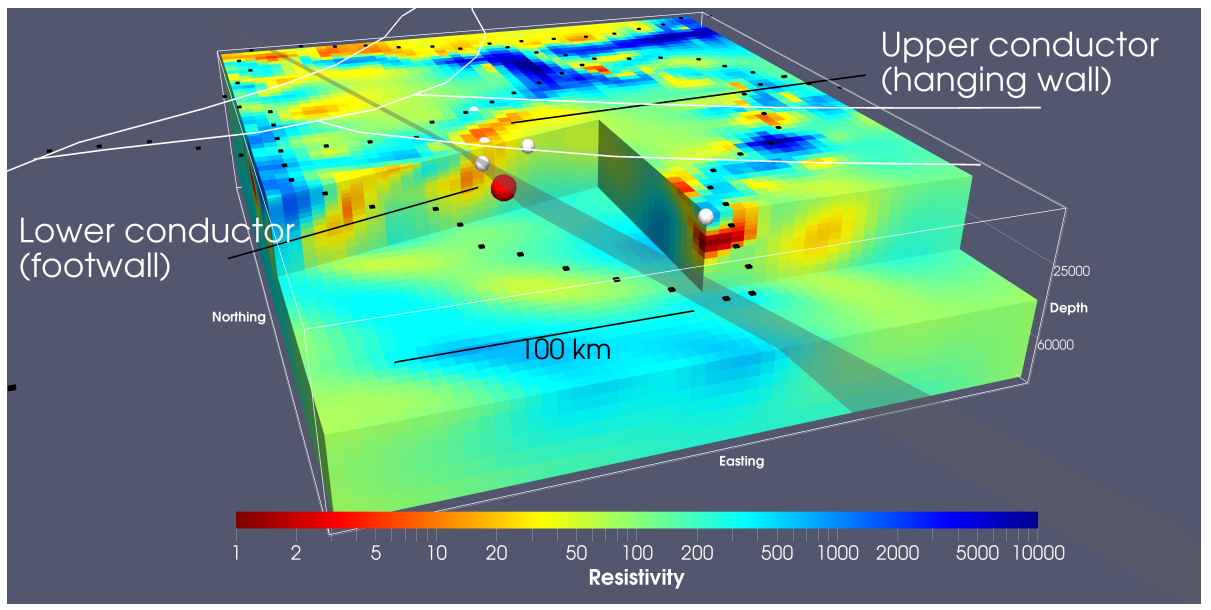

Figure 3: Cut through the preferred resistivity model viewed from the South-West. MT measurement site locations are marked by black squares and the location of the hypocentres are marked by dots. The main April 2017 event is marked in red and subsequent events in white. For the main event we plot the preferred fault plane from the moment tensor solution and D-InSAR modelling [27] as a transparent plane. The white lines mark the boundaries of major crustal units [26] 
RMS misfit of all sites considered in the inversion. Note that the apparent resistivities of the two off-diagonal components of impedance differ by two orders of magnitude, an indication of strong static distortion. Despite this, we achieve a reasonable fit to the observed data even though some of the more subtle features are not reproduced by the model.

The surface wave inversion uses a two stage approach to generate the tomographic models similar to the methodology outlined in [28]. The Rayleigh wave portion of the seismograms (periods of 50 - $120 \mathrm{~s}$ ) are inverted to find the average $1 \mathrm{D}$ shear $\left(S_{v}\right)$ velocity structure between source and receiver. In the approach taken here, for each waveform inversion four different starting models are used that incorporate prior information on crustal, and long wavelength mantle structure (see e.g., [28]). A particular advantage of incorporating the prior mantle structure in the starting models is that for the upper mantle there are significant differences between the general structure of oceans and continents. Using a 1D radially averaged starting model (such as PREM or ak135) will limit the recovery of the amplitude of anomalies beneath the different regions due to the necessary regularisation in the waveform inversion.

The resulting 1D velocity models are then combined to produce tomographic images, as a series of depth slices at $25 \mathrm{~km}$ intervals, of the lateral velocity variations within the upper mantle. To improve the reliability of these tomographic models, data from closely adjacent paths are clustered, this has the benefit of limiting the impact of $1 \mathrm{D}$ models that are not consistent with adjacent results, and somewhat downweighting areas that would be dominated by path coverage in one particular direction. For the recovery of the variations in velocity there are two steps in the inversion. Initially, a strongly damped inversion using over $>45,0001 \mathrm{D}$ models, is performed to recover the longest wavelength structure. Subsequently, the tomographic model is updated through an inversion using a parameterisation with knot points at 3-degree intervals. This intermediate stage provides good recovery of structures such as the mid ocean ridges and subduction zones, and therefore minimises the potential for these velocity features to be smeared into the final model. For the final inversion focused on 

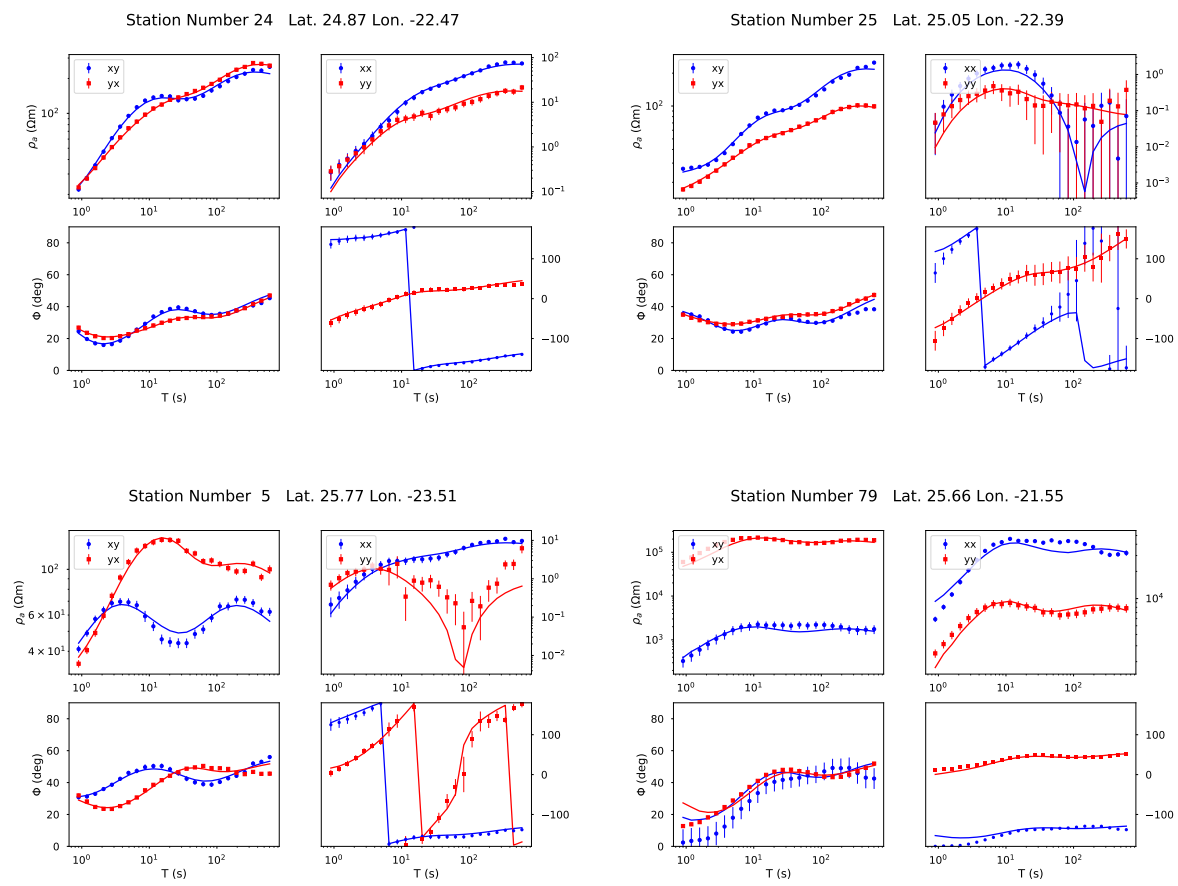

Figure 4: The fit of the final conductivity model for four selected MT sites. Stations 24 and 25 (top row) are the two stations closest to the main event. Station 5 (bottom left) is the MT site closest to the August 12th event. Station 79 (bottom right) has the highest misfit of all inverted MT stations. These sites are marked by red squares in Figure 2.

southern and east Africa a subset of paths is included, quantile-quantile plots are used to remove outliers (further limiting the impact of data that cannot be fit in the inversion procedure), and almost 19,500 paths are incorporated into the tomography (see Figure 5). The final models for each depth slice are chosen based on the trade off between data fit and a model norm regularisation. In this approach to regularisation, the specific choice of damping has an impact on the amplitude of the velocity anomalies, however the spatial location of variations in velocity in the resulting models remain consistent. Checkerboard tests illustrate that the path coverage in the region is sufficient to recover structures around $300 \mathrm{~km}$ in diameter with limited smearing (see Supplementary Information for associated figures). 


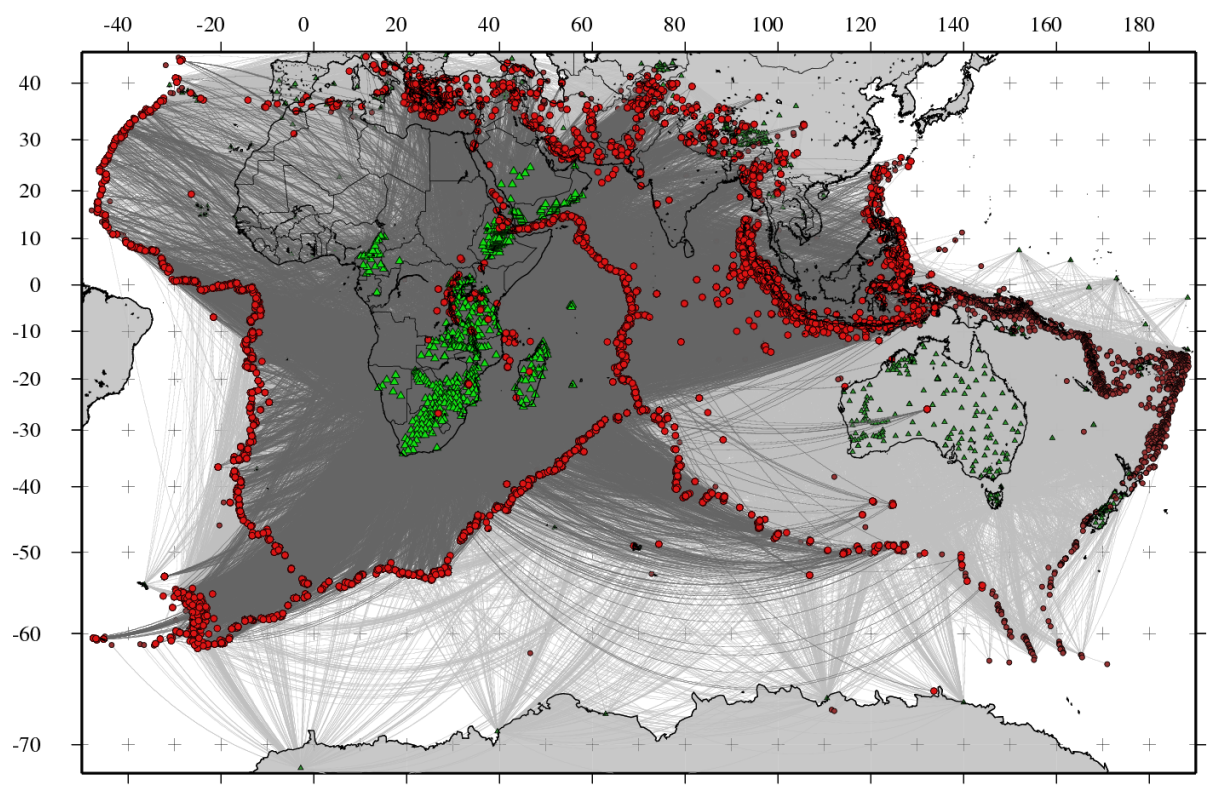

Figure 5: Events (red circles), stations (triangles) and path coverage (gray lines) used to construct the seismic surface wave model. The light gray paths show the coverage for the large scale model which is used as starting model for the regional model shown here. Dark gray paths indicate coverage for the final regional model. 


\section{Crustal structure}

Given the heterogeneous data coverage with the MT sites located on profiles along accessible roads, we focus our discussion of the resistivity model on structures close to these profiles. Our sensitivity tests demonstrate though that we have some sensitivity to off-profile structures (see Supplementary material). We estimate that we can recover structures up 1.5 skin depths in lateral direction and blank the areas in Figure 2 where we do not have sensitivity.

At depths between $15 \mathrm{~km}$ and $40 \mathrm{~km}$, most of the significant conductors (resistivity $\rho<25 \Omega \mathrm{m}$ ) terminate at geological boundaries (Figure 2). This is particularly evident for anomalies A, B, and C, but other conductive structures also show the same pattern. Resistive structure $\mathrm{D}$, which emerges at a depth of $30-40 \mathrm{~km}$, is bound on both sides by the inferred boundaries of the Proterozoicage Limpopo Belt. We note that the hypocentres of all seismic events in the region are located at the boundary of conductive structures (see Figures 3 and $6)$.

Conductors in the middle and lower crust can have a variety of origins depending on the geological setting. In strongly tectonically active areas they have been interpreted as accumulations of melt [e.g. 29]. This requires an unusually hot crust and thus can be ruled out in a stable continental setting. In such regions, enhanced conductivities at depths between 10 and $30 \mathrm{~km}$ are typically attributed to relatively small amounts of saline fluids [e.g. 30] or interconnected graphite and, to a lesser degree, sulphides [e.g. 31].

Regardless of which of these processes are considered, they all require the conductive phase to be interconnected over distances of several kilometres in order to cause an observable increase in conductivity. For graphite and sulphides, the simplest geological process to achieve such interconnectivity is deformation along shear zones creating thin boundary films [32]. Consequently many conductivity anomalies in the middle to lower crust have been interpreted as signs of significant deformation, particularly when there is strong variation in depth to the conductor $[16,31,33,34,35]$. Where fluids are considered to be the 
cause of enhanced conductivity, they are often thought to be trapped under an impermeable layer in the middle crust [36]. Large faults can breach such a seal and allow fluids to migrate upwards. This explanation has been invoked to explain the observed conductivities of major active fault systems such as the San Andreas Fault (SAF) [37, 38]. At the SAF, a deep (30-60 km) conductor is interpreted as a fluid reservoir that feeds a more shallow fault related fracture zone imaged as a narrow vertical conductor. Similar images and interpretations have been obtained in other active fault zones, e.g. the North Anatolian fault and the Niigata-Kobe Tectonic Zone in Japan [38]. In regions without significant ongoing tectonic activities, interconnected graphite is usually favoured as an explanation for fault related conductivity as fluids migrate upwards over geological time scales [33] and the deep conductor found in active regions appears to be missing. However, fluids can assist in transporting graphite during deformation and contribute to the formation of connected films [33].

Of particular interest for our study is the conductive structure associated with the hypocentre of the main event. Figure 3 shows a $3 \mathrm{D}$ cutout view of the preferred resistivity model together with the preferred fault plane solution based on the moment tensor, and the Differential Interferometric Synthetic Aperture Radar modelling of [27]. The inferred fault plane coincides with a significant change in depth of the crustal conductor in this area. In the foot wall on the western side its top is located at a depth of $14 \mathrm{~km}$, whereas in the hanging wall to the east, the conductor reaches the surface. Sensitivity tests (see supplementary material) demonstrate that we have good resolution to the depth of the deep conductor, and that the top on the eastern side cannot be located deeper than $7 \mathrm{~km}$.

Considering the above discussion of causes for high conductivity in fault zones, these structures could be a direct expression of fault related deformation or could be an originally continuous structure that has been displaced by movement on the fault. Given the spacing between the MT sites $(20 \mathrm{~km})$, we cannot directly image the fault zone, which is at most hundreds of meters wide. Instead we image the effect of the fault on the surrounding structures. Based 


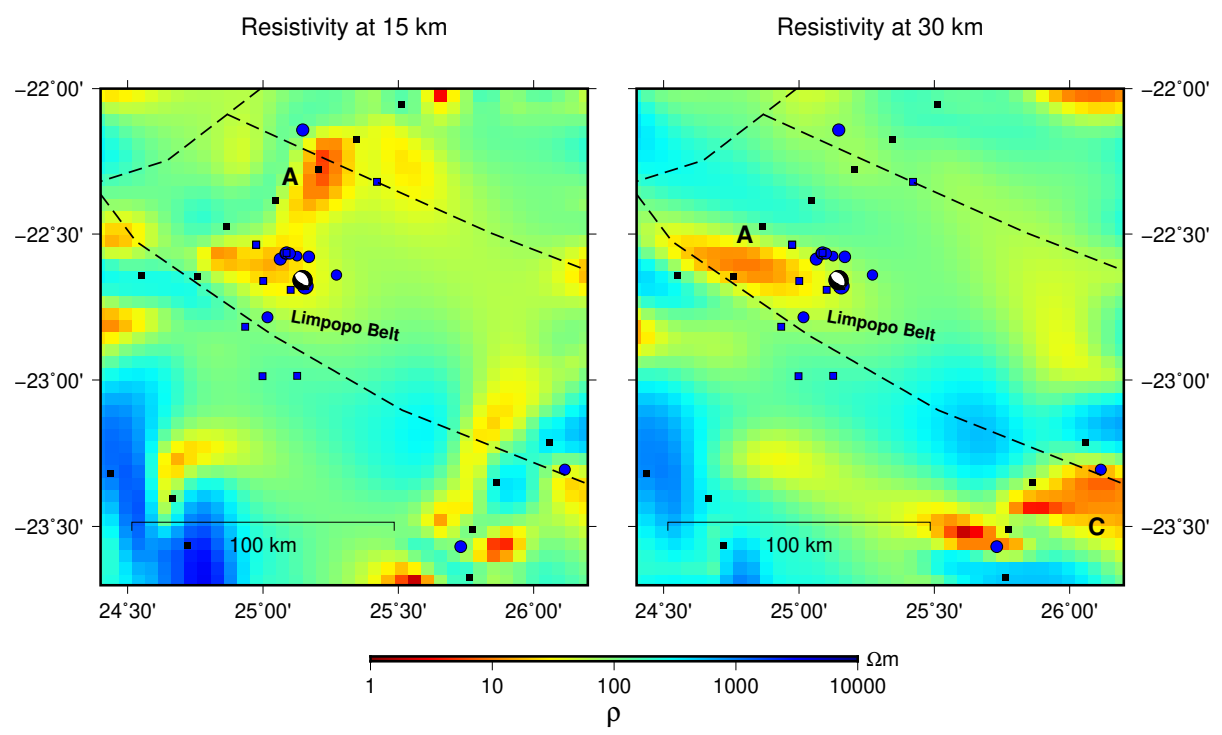

Figure 6: Magnified view of the model shown in Figure 2 around the earthquake sequence. The magnetotelluric stations in the area are marked as black squares. We show the location and focal mechanism of the April recent earthquake as well as the locations of seismicity in the area from the USGS catalogue (blue dots), the precursor locations determined in [10] (blue squares).

on the published estimates of the geometry of the fault for this event $[27,10]$, it is unlikely that we are imaging fluid pathways or shear signatures caused by the currently active fault. Instead it is more plausible that the two conductors were originally at the same depth and subsequently displaced by movement along the fault. However, the sense of motion necessary to produce such a displacement is opposite to the observed current fault motion. Thus our preferred interpretation is that the earthquake reactivated an existing thrust fault associated with the deformation associated with the collision of the Kaapvaal and Zimbabwe Cratons. This interpretation is consistent with other observations [27] and similar interpretations have been made for other paleo-faults [34].

The reactivation of an existing fault fits well with other studies of intra-plate earthquake nucleation [8]. However, the question remains to which degree the mid-crustal event corresponds also to deeper regional structure? In particular, 
can we identify a fluid reservoir that corroborates the hypothesis that this event was triggered by fluid released from the manlte [10]?

\section{Upper mantle structure}

In the context of deeper regional structure, Figure 7 shows the $S_{v}$ velocity for the region of southern Africa at depths of $75 \mathrm{~km}$ and $175 \mathrm{~km}$ (top row) and for the study area (bottom row), together with heat flow measurements [39], the directions of maximum horizontal stress [11] and relative plate motion from GPS data [12]. At $75 \mathrm{~km}$ depth the areas of the Kaapvaal and Zimbabwe cratons are clearly marked by high velocities $\left(v_{s}>4.6 \mathrm{~km} / \mathrm{s}\right)$, as expected for cold cratonic mantle. Similar fast velocities are observed beneath other areas of Archean age, e.g., the Tanzanian Craton, and fragments of the Congo Craton such as the Kazai shield. In the vicinity of the Botswanan earthquake we observe a low velocity structure $\left(v_{s} \approx 4.4 \mathrm{~km} / \mathrm{s}\right)$ at $75 \mathrm{~km}$ trending NW-SE and with a velocity minimum in the region of the earthquake. In contrast, at $175 \mathrm{~km}$ depth, fast velocities $\left(v_{s}>4.6 \mathrm{~km} / \mathrm{s}\right)$ typical of thick continental lithosphere are observed across a broader region of much of southeastern Botswana consistent with features observed in global tomographic models [40]. While low velocity zones in the upper mantle can represent zones of high temperature, and potentially partial melting, the underlying faster velocities make this explanation untenable. Although the heat flow measurements are moderately high (40-60 $\mathrm{mW} / \mathrm{m}^{2}$ ) away from the Kaapvaal and Zimbabwe Cratons [39, 41], the spatial variability and lack of correlation with velocities at $175 \mathrm{~km}$ depth, suggest a predominate crustal control on heat flow rather than variations due to lithospheric thickness.

Examining our resistivity model between 40 and $75 \mathrm{~km}$ (Figure 2), we see that the deep parts are generally resistive at depth with most parts exceeding resistivities of $500 \Omega \mathrm{m}$. Based on sensitivity tests (Supplementary material), we conclude that our data do not indicate a significant difference in resistivity between the Limpopo Belt and the surrounding Cratons at this depth and assume 
$75 \mathrm{~km}$ velocity map
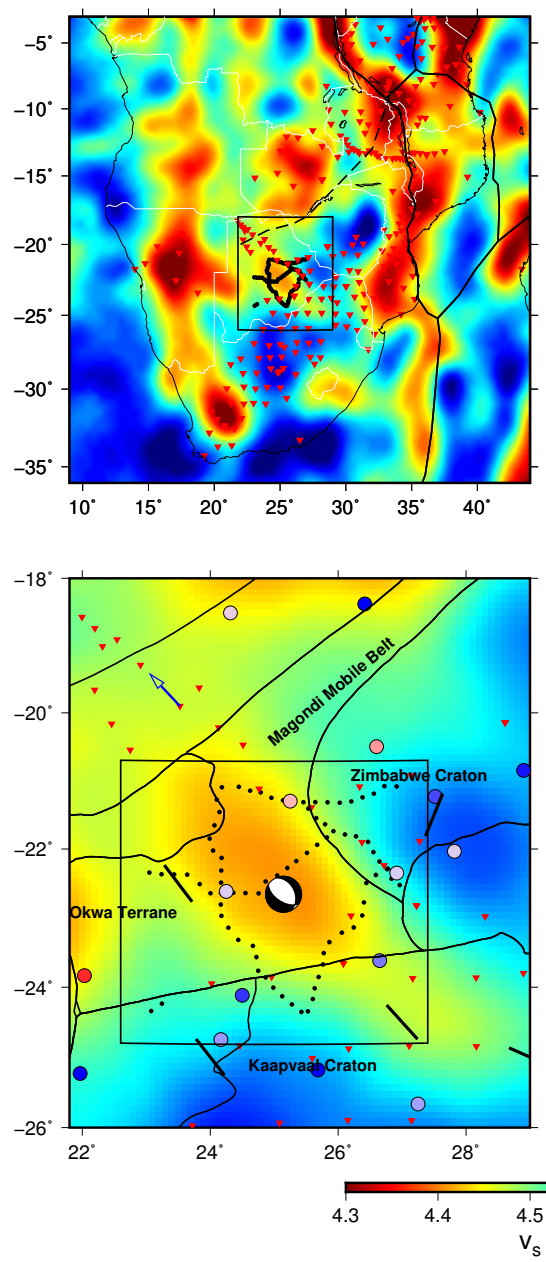

$175 \mathrm{~km}$ velocity map
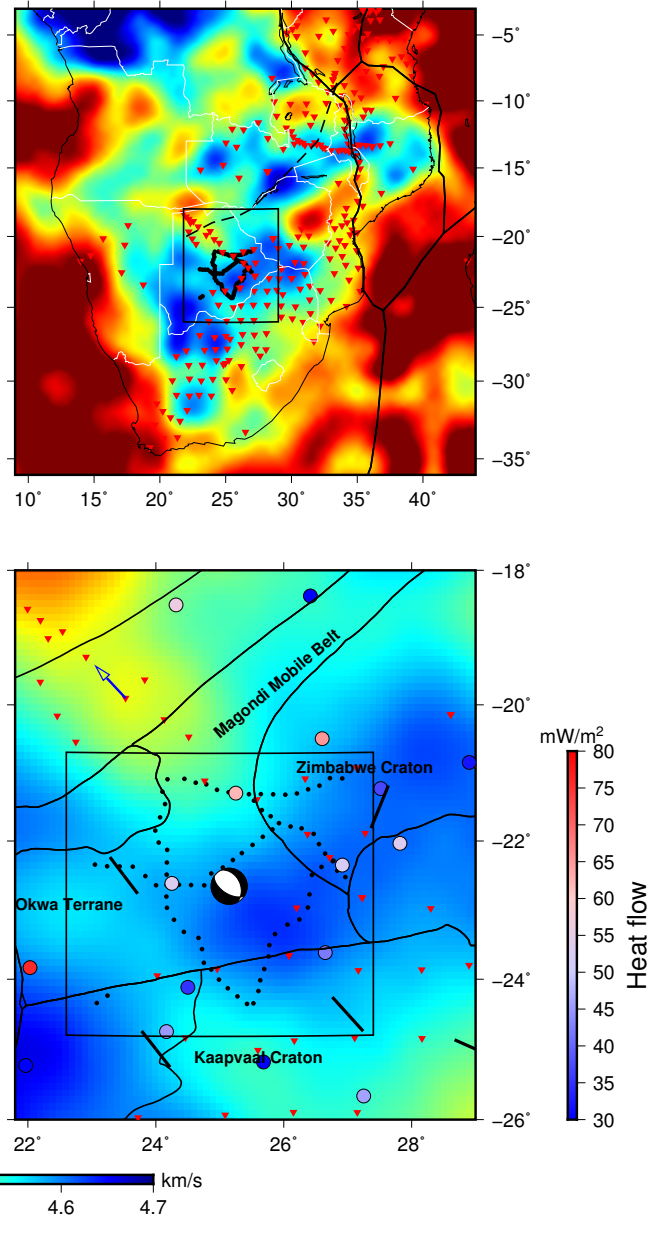

Figure 7: Horizontal slices through our regional surface wave model at depths of $75 \mathrm{~km}$ and $175 \mathrm{~km}$, respectively. The top row shows the wider southern African context, while the bottom row shows the region around the earthquake. In addition to stress orientations [11] (black bars), we also show the movement relative to the Nubian plate [12] (blue arrow) and heat flow measurements [39] (coloured dots) in the area. The seismic stations in the plotted area are shown as red triangles. 
values of $200-1000 \Omega \mathrm{m}$ as representative. Similar resistivities at these depths have also been observed in studies of the surrounding areas [16].

Dry Archean lithospheric mantle is expected to show resistivies in excess of $10,000 \Omega \mathrm{m}$ based on laboratory experiments within the typical compositional variations between Lherzolite and Harzburgite [23]. Such high resistivities are observed at the cores of the Kaapvaal Craton [42] and Congo Craton [16] at depths between 100-200 km, and in parts of the Slave Craton [43]. These high resistivity areas also show S-wave velocities exceeding $4.6 \mathrm{~km} / \mathrm{s}$ in the seismic velocity model as expected for old lithosphere. The resistivity values we observe cannot be explained by a dry mantle, but match the range of resistivities of 500$2000 \Omega \mathrm{m}$ estimated at this depth for typical mantle compositions with a water content of $150 \mathrm{ppm}$ [44]. Such a water content agrees well with the estimated average water content of the lithospheric mantle [45]. Calculations of S-wave velocity for a range of compositions and temperature profiles predict values in excess of $4.5 \mathrm{~km} / \mathrm{s}$ at a depth of $80 \mathrm{~km}$ [46] which matches the values we observe towards the south, in the Kaapvaal Craton, but is significantly higher than the velocities recovered around the epicentre. So, while the resistivity model indicates a relatively homogeneous, normal lithospheric mantle structure, the seismic model requires a strong change in physical properties between the cratons in the south and the region of the epicentre.

\section{Discussion and conclusions}

It has been suggested that the event was triggered by fluid release from the mantle bringing a critically loaded fault network to failure [10]. The crustal structure in our resistivity model is compatible with such a scenario. As explained above, we cannot directly image the fault zone as this would require denser site spacing near the fault and higher frequency data than what is currently available. The two displaced conductive structures could be fluid related although this would require some form of seal to prevent those fluids from migrating upwards. For this reason we consider an explanation in terms of graphite 
more likely. Even if the high conductivity in the crust is at least partially caused by saline fluids, these structures cannot be the source for the fluid pulse that triggered the event, as the epicentre is located below these conductors at the transition to more resistive material.

A major region of elevated fluid content in the mantle would manifest itself as a region of high conductivity [37]. We do not see such structures in our model. In fact, the lack of strong variation in resistivity in the upper mantle underneath the study area, suggests a homogeneous thermal structure and water content as these are the two major controlling factors on resistivity in the nominally anhydrous minerals (NAMs) of the lithosphere [47]. Therefore, either the source region of the fluids is spatially restricted (less than a few kilometres in diameter), the fluids are derived from moderate amounts of ambient water in the mantle or another triggering mechanism is responsible. Based on our results, we cannot distinguish between these alternatives. Thus, although our model does not show the expected features of a mantle fluid reservoir, we cannot refute the hypothesis put forward by [10].

We will now focus the discussion on the potential origins of the low velocity zone at $80 \mathrm{~km}$ depth. Variations in temperature or water content would result in observable resistivity variations [47]. We can therefore exclude these two variables as an explanation for the low velocities. Furthermore, both have a similar effect on resistivity and seismic velocity and thus an increase in temperature accompanied by a decrease in water content or vice versa is not feasible either. This leaves two possible explanations for a decrease in velocity that is not accompanied by a change in resistivity: i) Variations in mantle composition and ii) variations in grain size of olivine. A bulk compositional change compatible with our observations would have to maintain iron content (or equivalently Magnesium number: $\mathrm{Mg} \#)$ as variations in $\mathrm{Mg} \#$ have observable effects on conductivity [23].

Compositional explanations for low velocities in the uppermost lithosphere have been discussed previously. [48] suggested qualitatively that paragasitic amphiboles could contribute to lowering velocities in central Australia, in a region 
of thick lithosphere, but noted that this would require a complicated layered structure with no clear mechanism of formation. The presence of chrome, thus lowering the depth of the spinel transition, has been invoked as a possible explanation for the velocity gradients seen in Precambrian lithosphere of a number of areas [49]. Modelling of phase velocity profiles for cratonic regions also indicated that models of constant composition have a systematic variation from the seismic data [50] and further studies using these data indicate that a metasomatic component (water or carbonate fluids) improve the fit to the seismological observations [51]. However, the velocity variations observed in our study region have larger variations than those modelled in [51].

The idea of enhanced concentrations of amphibole, has been revisited, and invoked to explain low velocities at a similar depth range and magnitude inferred from S-receiver functions [52]. The electrical resistivity of amphiboles at upper mantle conditions is currently unclear, but laboratory measurements under lower crustal conditions suggest a significant decrease in resistivity from amphibole enrichment [53]. We therefore cannot rule out amphibole as a source of the observed low velocities, but consider the high concentrations $(\sim 20 \%)$ invoked by [52] to explain a similar magnitude low velocity anomaly improbable.

Variations in grain size have been shown to affect seismic velocities in the mantle and a reduction in size from approximately $1 \mathrm{~cm}$ below the cratons to several millimeters below the mobile belt is sufficient to explain the lower seismic velocities below the Limpopo mobile belt [54]. Such sizes are consistent with estimated values in undeformed cratonic lithosphere and deformed mobile belts, respectively [55]. Electrical resistivity shows dependence on grain size for sizes below $1 \mathrm{~mm}$, but for the range of sizes considered here is negligible [47]. Deformation can result in a grain size reduction in the upper mantle that can persist for several hundred million years [56]. Thus we consider a reduced grain size below the Limpopo belt the most likely explanation for our observations. Interestingly, our two most likely explanations, reduced grain size and amphibole enrichment are typically observed in samples from mantle shear zones[57]. Furthermore, a reduced grain size results in a reduced viscosity [55] 
indicating that the low velocity zone underneath the Botswana earthquake is an expression of a weak mantle.

Our combined magnetotelluric and seismic study demonstrates that the recent Botswana earthquake sequence reactivated previous faults in the area. For the main event, this reactivation occurs in the opposite sense to the original fault movement. All events occur above a region of low velocities and relatively high resistivities in the upper-most mantle that we interpret as a region of reduced grain size and thus weaker material compared to its surroundings. The observed extensional fault movement is compatible with the ambient stress pattern in southern Africa. Our results can neither confirm nor refute the proposed triggering of the event by mantle derived fluids. We do however see signs of a rheologically weak upper mantle. The lack of a significant deep lithospheric thermal anomaly then suggests that this process is initiated from the top, through interaction of the ambient stress field with ancient structures, rather than through thermal weakening from below.

[1] F. Krüger, F. Scherbaum, The 29 September 1969, Ceres, South Africa, earthquake: Full waveform moment tensor inversion for point source and kinematic source parameters, Bulletin of the Seismological Society of America 104 (1) (2014) 576-581.

[2] P. Talwani, The intersection model for intraplate earthquakes, Seismological Research Letters 59 (4) (1988) 305-310.

[3] L. R. Sykes, M. L. Sbar, Intraplate earthquakes, lithospheric stresses and the driving mechanism of plate tectonics, Nature 245 (5424) (1973) 298302.

[4] D. E. McNamara, H. M. Benz, R. B. Herrmann, E. A. Bergman, P. Earle, A. Holland, R. Baldwin, A. Gassner, Earthquake hypocenters and focal mechanisms in central Oklahoma reveal a complex system of reactivated subsurface strike-slip faulting, Geophysical Research Letters 42 (8) (2015) 2742-2749. 
[5] D. D. Coblentz, M. Sandiford, Tectonic stresses in the african plate: Constraints on the ambient lithospheric stress state, Geology 22 (9) (1994) 831-834.

[6] D. Stamps, L. Flesch, E. Calais, Lithospheric buoyancy forces in africa from a thin sheet approach, International Journal of Earth Sciences 99 (7) (2010) 1525-1533.

[7] W. D. Mooney, J. Ritsema, Y. K. Hwang, Crustal seismicity and the earthquake catalog maximum moment magnitude (mcmax) in stable continental regions (scrs): Correlation with the seismic velocity of the lithosphere, Earth and planetary science letters 357 (2012) 78-83.

[8] S. J. Kenner, P. Segall, A mechanical model for intraplate earthquakes: Application to the New Madrid seismic zone, Science 289 (5488) (2000) 2329-2332.

[9] E. Calais, T. Camelbeeck, S. Stein, M. Liu, T. Craig, A new paradigm for large earthquakes in stable continental plate interiors, Geophysical Research Letters $43(20)$.

[10] B. Gardonio, R. Jolivet, E. Calais, H. Leclère, The April 2017 Mw6. 5 Botswana earthquake: An intraplate event triggered by deep fluids, Geophysical Research Letters.

[11] O. Heidbach, M. Rajabi, K. Reiter, M. Ziegler, W. Team, World stress map database release 2016, Tech. rep., GFZ Data Services (2016). doi:10.5880/WSM.2016.001.

URL http://doi.org/10.5880/WSM.2016.001

[12] E. Saria, E. Calais, Z. Altamimi, P. Willis, H. Farah, A new velocity field for Africa from combined GPS and DORIS space geodetic solutions: Contribution to the definition of the African reference frame (AFREF), Journal of Geophysical Research: Solid Earth 118 (4) (2013) 1677-1697. 
[13] C. Reeves, Rifting in the Kalahari?, Nature 237 (5350) (1972) 95-96.

[14] K. Leseane, E. A. Atekwana, K. L. Mickus, M. G. Abdelsalam, E. M. Shemang, E. A. Atekwana, Thermal perturbations beneath the incipient Okavango Rift zone, northwest Botswana, Journal of Geophysical Research: Solid Earth 120 (2) (2015) 1210-1228, 2014JB011029. doi:10.1002/2014JB011029.

[15] Y. Yu, K. H. Liu, Z. Huang, D. Zhao, C. A. Reed, M. Moidaki, J. Lei, S. S. Gao, Mantle structure beneath the incipient Okavango rift zone in southern Africa, Geosphere 13 (1) (2017) 102-111.

[16] T. D. Khoza, A. G. Jones, M. R. Muller, R. L. Evans, M. P. Miensopust, S. J. Webb, Lithospheric structure of an Archean craton and adjacent mobile belt revealed from 2-D and 3-D inversion of magnetotelluric data: Example from southern Congo Craton in northern Namibia, Journal of Geophysical Research: Solid Earth 118 (8) (2013) 4378-4397.

[17] Y. Yu, K. H. Liu, M. Moidaki, C. A. Reed, S. S. Gao, No thermal anomalies in the mantle transition zone beneath an incipient continental rift: evidence from the first receiver function study across the Okavango rift zone, botswana, Geophysical Journal International 202 (2) (2015) 1407-1418.

[18] Y. Yu, S. S. Gao, M. Moidaki, C. A. Reed, K. H. Liu, Seismic anisotropy beneath the incipient Okavango rift: Implications for rifting initiation, Earth and Planetary Science Letters 430 (2015) 1-8.

[19] R. Ranganai, A. Kampunzu, E. Atekwana, B. Paya, J. King, D. Koosimile, E. Stettler, Gravity evidence for a larger Limpopo Belt in southern Africa and geodynamic implications, Geophysical Journal International 149 (3) (2002) F9-F14.

[20] A.-M. Pastier, O. Dauteuil, M. Murray-Hudson, F. Moreau, A. Walpersdorf, K. Makati, Is the Okavango delta the terminus of the East African Rift System? towards a new geodynamic model: Geodetic 
study and geophysical review, Tectonophysics 712 (2017) 469 - 481. doi:http://dx.doi.org/10.1016/j.tecto.2017.05.035.

[21] I. Fadel, M. van der Meijde, H. Paulssen, Crustal structure and dynamics of Botswana, Journal of Geophysical Research: Solid Earth accepted (ja). doi:10.1029/2018JB016190.

[22] A. Jones, S. Fishwick, R. Evans, M. Muller, J. Fullea, Velocity-conductivity relations for cratonic lithosphere and their application: Example of Southern Africa, Geochemistry, Geophysics, Geosystems 14 (4) (2013) 806-827.

[23] A. G. Jones, R. L. Evans, M. R. Muller, M. P. Hamilton, M. P. Miensopust, X. Garcia, P. Cole, T. Ngwisanyi, D. Hutchins, C. Fourie, H. Jelsma, S. Evans, T. Aravanis, W. Pettit, S. Webb, J. Wasborg, The SAMTEX Team, Area selection for diamonds using magnetotellurics: Examples from Southern Africa, Lithos 112 (Supplement 1) (2009) 83 - 92. doi:10.1016/j.lithos.2009.06.011.

[24] D. Avdeev, A. Avdeeva, 3d magnetotelluric inversion using a limitedmemory quasi-newton optimization, Geophysics 74 (3) (2009) F45-F57. doi:10.1190/1.3114023.

[25] A. Avdeeva, M. Moorkamp, D. Avdeev, M. Jegen, M. Miensopust, Threedimensional inversion of magnetotelluric impedance tensor data and full distortion matrix, Geophysical Journal International 202 (1) (2015) 464481.

[26] R. Brown, T. Gernon, J. Stiefenhofer, M. Field, Geological constraints on the eruption of the Jwaneng Centre kimberlite pipe, Botswana, Journal of Volcanology and Geothermal Research 174 (1) (2008) 195-208.

[27] F. Kolawole, E. A. Atekwana, S. Malloy, D. S. Stamps, R. Grandin, M. G. Abdelsalam, K. Leseane, E. M. Shemang, Aeromagnetic, gravity, and differential interferometric synthetic aperture radar analyses reveal the causative fault of the 3 April $2017 \mathrm{mw}$ 6.5 Moiyabana, Botswana, 
earthquake, Geophysical Research Letters (2017) n/a-n/a2017GL074620. doi:10.1002/2017GL074620.

[28] S. Fishwick, Surface wave tomography: Imaging of the lithosphereasthenosphere boundary beneath central and southern Africa?, Lithos 120 (1-2) (2010) 63-73.

[29] F. Le Pape, A. G. Jones, J. Vozar, W. Wenbo, Penetration of crustal melt beyond the Kunlun Fault into northern Tbet, Nature Geoscience 5 (5) (2012) 330.

[30] M. Unsworth, S. Rondenay, Mapping the distribution of fluids in the crust and lithospheric mantle utilizing geophysical methods, in: Metasomatism and the Chemical Transformation of Rock, Springer, 2013, pp. 535-598.

[31] C. K. Rao, A. G. Jones, M. Moorkamp, The geometry of the Iapetus Suture Zone in central Ireland deduced from a magnetotelluric study, Physics of the Earth and Planetary Interiors 161 (2007) 134-141. doi:10.1016/j.pepi.2007.01.008.

[32] W. Heise, S. Ellis, On the coupling of geodynamic and resistivity models: a progress report and the way forward, Surveys in Geophysics 37 (1) (2016) 81-107.

[33] O. Ritter, U. Weckmann, T. Vietor, V. Haak, A magnetotelluric study of the damara belt in namibia: 1. regional scale conductivity anomalies, Physics of the Earth and Planetary Interiors 138 (2) (2003) 71-90.

[34] U. Weckmann, Making and breaking of a continent: Following the scent of geodynamic imprints on the african continent using electromagnetics, Surveys in geophysics 33 (1) (2012) 107-134.

[35] M. P. Miensopust, A. G. Jones, M. R. Muller, X. Garcia, R. L. Evans, Lithospheric structures and precambrian terrane boundaries in northeastern Botswana revealed through magnetotelluric profiling as part of the 
Southern African Magnetotelluric Experiment, Journal of Geophysical Research: Solid Earth 116 (B2).

[36] R. Hyndman, P. Shearer, Water in the lower continental crust: modelling magnetotelluric and seismic reflection results, Geophysical Journal International 98 (2) (1989) 343-365.

[37] M. Becken, O. Ritter, P. Bedrosian, U. Weckmann, Correlation between deep fluids, tremor and creep along the central san andreas fault, Nature 480 (7375) (2011) 87-90.

[38] M. Becken, O. Ritter, Magnetotelluric studies at the san andreas fault zone: implications for the role of fluids, Surveys in Geophysics 33 (1) (2012) 65105.

[39] D. Hasterock, The global heat flow database of the international heat flow commission, http://www.heatflow.und.edu/index2.html.

[40] A. Schaeffer, S. Lebedev, Global shear speed structure of the upper mantle and transition zone, Geophysical Journal International 194 (1) (2013) 417449.

[41] S. Ballard, H. N. Pollack, N. J. Skinner, Terrestrial heat flow in botswana and namibia, Journal of Geophysical Research: Solid Earth 92 (B7) (1987) 6291-6300. doi:10.1029/JB092iB07p06291.

[42] R. L. Evans, A. G. Jones, X. Garcia, M. Muller, M. Hamilton, S. Evans, C. Fourie, J. Spratt, S. Webb, H. Jelsma, et al., Electrical lithosphere beneath the Kaapvaal craton, southern Africa, Journal of Geophysical Research: Solid Earth 116 (B4).

[43] A. G. Jones, J. Ledo, I. J. Ferguson, C. Farquharson, X. Garcia, N. Grant, G. McNeice, B. Roberts, J. Spratt, G. Wennberg, et al., The electrical resistivity structure of Archean to Tertiary lithosphere along $3200 \mathrm{~km}$ of SNORCLE profiles, northwestern Canada, Canadian Journal of Earth Sciences 42 (6) (2005) 1257-1275. 
[44] K. Selway, Electrical discontinuities in the continental lithosphere imaged with magnetotellurics, in: H. Yuan, B. Romanowicz (Eds.), Lithospheric Discontinuities, John Wiley \& Sons, Inc, 2019, pp. 89-109.

[45] M. M. Hirschmann, Water, melting, and the deep earth h2o cycle, Annu. Rev. Earth Planet. Sci. 34 (2006) 629-653.

[46] A. Zunino, A. Khan, P. Cupillard, K. Mosegaard, Constitution and Structure of Earth's Mantle, John Wiley \& Sons, Inc, 2016, pp. 219-243. doi:10.1002/9781118929063.ch11. URL http://dx.doi.org/10.1002/9781118929063.ch11

[47] A. G. Jones, Proton conduction and hydrogen diffusion in olivine: an attempt to reconcile laboratory and field observations and implications for the role of grain boundary diffusion in enhancing conductivity, Physics and Chemistry of Minerals 43 (4) (2016) 237-265.

[48] S. Fishwick, A. Reading, Anomalous lithosphere beneath the proterozoic of western and central australia: a record of continental collision and intraplate deformation?, Precambrian Research 166 (1-4) (2008) 111-121.

[49] S. Lebedev, J. Boonen, J. Trampert, Seismic structure of precambrian lithosphere: New constraints from broad-band surface-wave dispersion, Lithos 109 (1-2) (2009) 96-111.

[50] H. Pedersen, S. Fishwick, D. Snyder, A comparison of cratonic roots through consistent analysis of seismic surface waves, Lithos 109 (1-2) (2009) 81-95.

[51] T. Eeken, S. Goes, H. A. Pedersen, N. T. Arndt, P. Bouilhol, Seismic evidence for depth-dependent metasomatism in cratons, Earth and Planetary Science Letters 491 (2018) 148-159.

[52] K. Selway, H. Ford, P. Kelemen, The seismic mid-lithosphere discontinuity, Earth and Planetary Science Letters 414 (2015) 45-57. 
[53] D. Wang, Y. Guo, Y. Yu, S.-i. Karato, Electrical conductivity of amphibolebearing rocks: influence of dehydration, Contributions to Mineralogy and Petrology 164 (1) (2012) 17-25. doi:10.1007/s00410-012-0722-z.

[54] U. H. Faul, I. Jackson, The seismological signature of temperature and grain size variations in the upper mantle, Earth and Planetary Science Letters 234 (1) (2005) 119-134.

[55] K. Selway, Negligible effect of hydrogen content on plate strength in East Africa, Nature Geoscience 8 (7) (2015) 543.

[56] D. Bercovici, Y. Ricard, Mechanisms for the generation of plate tectonics by two-phase grain-damage and pinning, Physics of the Earth and Planetary Interiors 202 (Supplement C) (2012) 27 - 55. doi:https://doi.org/10.1016/j.pepi.2012.05.003.

[57] R. Vissers, M. Drury, E. Hoogerduijn, C. Spiers, D. Van der Wal, et al., Mantle shear zones and their effect on lithosphere strength during continental breakup, Tectonophysics 249 (3-4) (1995) 155-171.

[58] P. Wessel, W. H. Smith, New, improved version of the generic mapping tools released, EOS Trans. AGU 79 (1998) 579.

\section{Acknowledgements}

All magnetotelluric data used in this study can be downloaded from http://www.completemt-solutions.com/mtnet/data/samtex/samtex.html. The surface wave model was generated using seismic waveform data are available from the seismological data centres, IRIS and GEOFON Potsdam. Where waveform data are not currently open access (due to a moratorium following deployment) principal investigators of the seismic experiments should be contacted (see below for information). 
The authors wish to acknowledge the tremendous contribution made to this work by all those people involved in the numerous deployments for seismological and magnetotelluric data acquisition across southern Africa. In addition to the funding and logistical support provided by SAMTEX consortium members (Council for Geoscience, Geological Surveys Botswana and Namibia, De Beers Group Services, Rio Tinto Exploration, and BHP Billiton), this work was also supported by research grants from National Science Foundations Continental Dynamics program (USA, EAR0309584 and EAR0455242), the Department of Science and Technology (South Africa), and Science Foundation Ireland (Ireland, grant 05/RFP/GEO001). We also thank the many farmers and landowners in Botswana, Namibia, and South Africa for their voluntary cooperation in allowing the deployment of MT stations on their properties. Seismic data has been accessed from the IRIS data management centre, and GFZ Potsdam. Particular thanks are given to Cindy Ebinger, Georg Ruempker and Donna Shillington for access to data that was not publically available at the time of preparation. Figures 1, 2, 6 and 7 are plotted using the Generic Mapping Tools[58]. This research used the ALICE High Performance Computing Facility at the University of Leicester. Finally, we would like to than E. Calais, an anonymous reviewer and the editor J. Brodholt for their comments that improved the quality of the manuscript. 